\title{
A giant intraperineal and extraperineal mass
}

\author{
Giancarlo D'Andrea, ${ }^{1}$ Pietro Familiari, ${ }^{1}$ Laura Lorenzon, ${ }^{2}$ Giuseppe Argento, ${ }^{3}$ \\ Antonino Raco, ${ }^{1}$ Vincenzo Ziparo ${ }^{2}$
}

${ }^{1}$ Division of Neurosurgery, Department of Neurosciences, Organ Senses and Mental Health, Faculty of Medicine and Psychology, University of Rome "La Sapienza", Rome, Italy

${ }^{2}$ Surgery 1 Unit, Surgical and Medical Department of Traslational Medicine, Faculty of Medicine and Psychology, University of Rome "La Sapienza", Rome, Italy ${ }^{3}$ Radiology Unit, Surgical and Medical Department of Traslational Medicine, Faculty of Medicine and Psychology, University of Rome "La Sapienza", Rome, Italy

\section{Correspondence to}

Professor Laura Lorenzon, laura.lorenzon@uniroma1.it

Accepted 8 September 2014

\section{DESCRIPTION}

A 67-year-old woman was admitted to our hospital with severe low back/radicular pain and gait disturbance, and presenting a giant extraperineal mass (figure 1).

A preoperative CT scan documented a mixed fluid/ solid mass measuring $35 \times 19 \times 18 \mathrm{~cm}$ dislocating the rectum and protruding outside the perineum in the infragluteal space, which was also associated with a sacrococcygeal malformation consistent with a coccyx's cleft, as confirmed by MRI.

The patient reported the presence of a smaller sacrococcygeal mass since childhood, which increased in size over the past 3 years; she did not
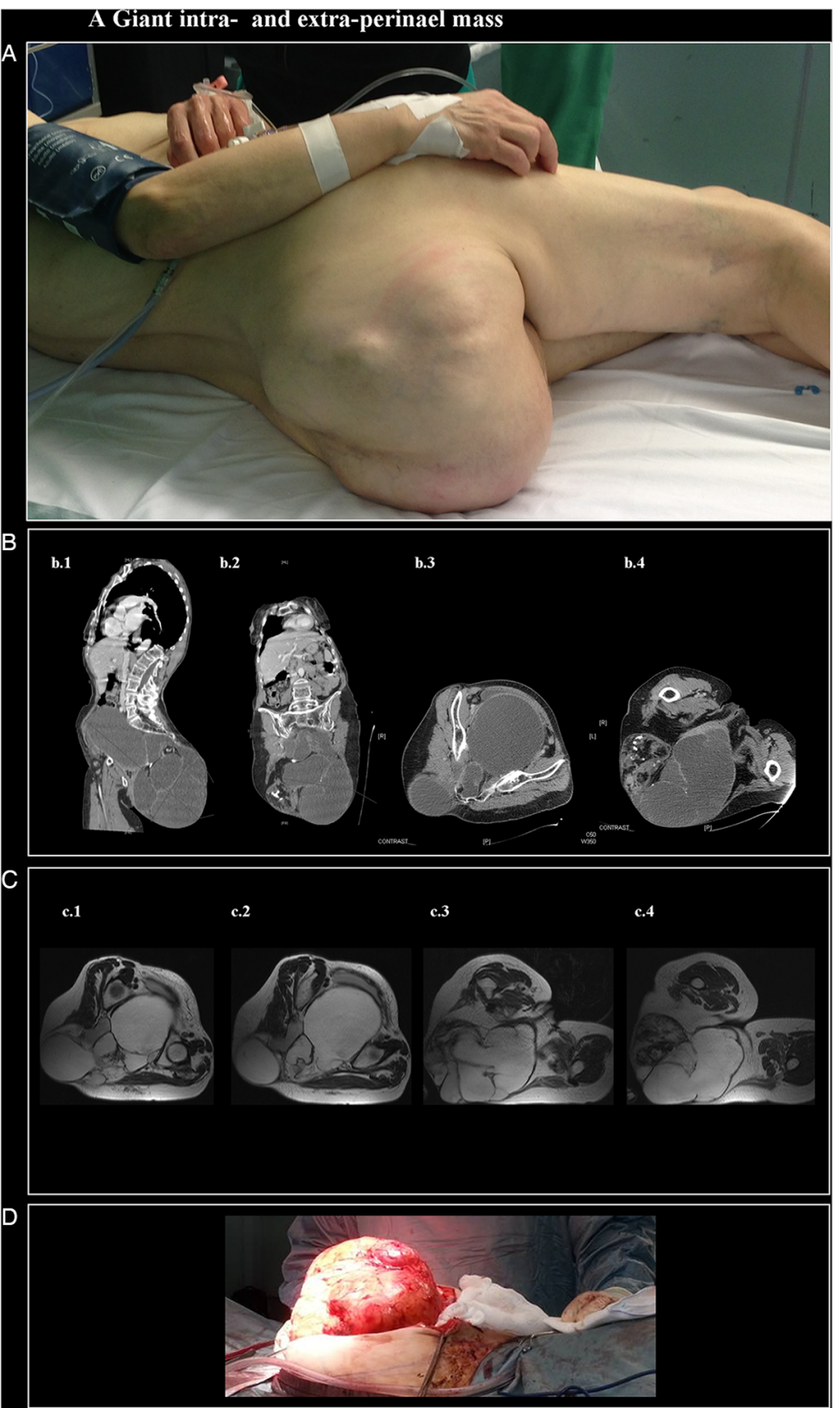

Figure 1 (A) Clinical appearance of the perineal mass protruding outside the perineum in the infragluteal space ('queen bee' shape). (B) Preoperative iodine contrast-enhanced CT scan documenting the tumour: (B1 and B2) CT sagittal and coronal multiplanar rendering views: in the $\mathrm{CT}$ reformation images both intrapelvic and extraperineal components of the mass are shown; CT axial images: (B3) pelvic involvement and superior aspect of the extraperineal mass; (B4) axial plane at the level of the proximal third of the thighs documenting the maximum diameter of the extraperineal component. (C) MRI: turbo spin-echo T2-weighted axial images at different levels; (C1 and C2) intrapelvic extension of the mass in the retroperitoneal space and in the posterior sacral region; (C3 and C4) perineal and intraperineal major cystic component close to the left para-sagittal plain, adjacent to the proximal left thigh. (D) Posterior surgical approach to the tumour. 
consider a medical consultation, however, due to a major depressive disorder.

The patient was scheduled for a surgical procedure and the tumour was completely removed via a posterior approach. The pathological examination documented a teratoma with focal areas of malignant transformation.

Sacrococcygeal teratomas (SCTs) are germ cell tumours, with an incidence of 1/40 000 live-births, affecting females 4 times more often than males. ${ }^{12}$

\section{Learning points}

Because the clinical manifestations of presacral masses are often non-specific, imaging plays an important role in the detection and differentiation of these masses and might be crucial for their surgical management.

- Sacro-coccygeal teratomas affect females more often than males.

- Up to one-fourth of the SCT might be malignant and the risk is increased in adult patients.
SCTs are the most common presacral germ cell tumours in children and neonates. Up to $27 \%$ of SCTs are malignant, and the probability of malignancy increases with the age of presentation. $^{1}$

SCTs are classified according to Altman classification into: type I, predominantly external masses with a small presacral component; type II, external masses with a significant intrapelvic component; type III, external masses with a pelvic and abdominal component; and type IV, internal masses with an intrapelvic and abdominal location; types II and III are dumbbell shaped. ${ }^{3}$

Contributors All authors contributed to writing the manuscript; and reviewed and approved the manuscript in its final form.

Competing interests None.

Patient consent Obtained.

Provenance and peer review Not commissioned; externally peer reviewed.

\section{REFERENCES}

1 Peterson CM, Buckley C, Holley $\mathrm{S}$, et al. Teratomas: a multimodality review. Curr Probl Diagn Radiol 2012;41:210-19.

2 Kocaoglu M, Frush DP. Pediatric presacral masses. RadioGraphics 2006;26:833-57.

3 Altman RP, Randolph JG, Lilly JR. Sacrococcygeal teratoma: American Academy of Pediatrics Surgical Section Survey—1973. J Pediatr Surg 1974;9:389-98.

Copyright 2014 BMJ Publishing Group. All rights reserved. For permission to reuse any of this content visit http://group.bmi.com/group/rights-licensing/permissions.

BMJ Case Report Fellows may re-use this article for personal use and teaching without any further permission.

Become a Fellow of BMJ Case Reports today and you can:

- Submit as many cases as you like

- Enjoy fast sympathetic peer review and rapid publication of accepted articles

- Access all the published articles

- Re-use any of the published material for personal use and teaching without further permission

For information on Institutional Fellowships contact consortiasales@bmjgroup.com

Visit casereports.bmj.com for more articles like this and to become a Fellow 